OPEN ACCESS

Edited by:

Giovanna Suzzi,

Università di Teramo, Italy

Reviewed by:

Soohyoun Ahn,

University of Florida, United States

Lucia Galli,

National University of La Plata,

Argentina

*Correspondence:

Alejandro Garrido-Maestu alejandro.garrido@inl.int

Specialty section:

This article was submitted to

Food Microbiology,

a section of the journal

Frontiers in Microbiology

Received: 09 August 2017 Accepted: 20 October 2017

Published: 06 November 2017

Citation:

Garrido-Maestu A, Azinheiro S, Carvalho J, Abalde-Cela S,

Carbó-Argibay E, Diéguez L,

Piotrowski M, Kolen'ko $\mathrm{W}$ and

Prado M (2017) Combination

of Microfluidic Loop-Mediated

Isothermal Amplification with Gold

Nanoparticles for Rapid Detection

of Salmonella spp. in Food Samples.

Front. Microbiol. 8:2159.

doi: 10.3389/fmicb.2017.02159

\section{Combination of Microfluidic Loop-Mediated Isothermal Amplification with Gold Nanoparticles for Rapid Detection of Salmonella spp. in Food Samples}

\author{
Alejandro Garrido-Maestu*, Sarah Azinheiro, Joana Carvalho, Sara Abalde-Cela, \\ Enrique Carbó-Argibay, Lorena Diéguez, Marek Piotrowski, Yury V. Kolen'ko and \\ Marta Prado
}

International Iberian Nanotechnology Laboratory, Braga, Portugal

Foodborne diseases are an important cause of morbidity and mortality. According to the World Health Organization, there are 31 main global hazards, which caused in 2010 600 million foodborne illnesses and 420000 deaths. Among them, Salmonella spp. is one of the most important human pathogens, accounting for more than 90000 cases in Europe and even more in the United States per year. In the current study we report the development, and thorough evaluation in food samples, of a microfluidic system combining loop-mediated isothermal amplification with gold nanoparticles (AuNPs). This system is intended for low-cost, in situ, detection of different pathogens, as the proposed methodology can be extrapolated to different microorganisms. A very low limit of detection (10 cfu/25 g) was obtained. Furthermore, the evaluation of spiked food samples (chicken, turkey, egg products), completely matched the expected results, as denoted by the index kappa of concordance (value of 1.00). The results obtained for the relative sensitivity, specificity and accuracy were of $100 \%$ as well as the positive and negative predictive values.

Keywords: microfluidics, gold nanoparticles, Salmonella spp., LAMP, invA

\section{INTRODUCTION}

Salmonella spp. continues to be a major health issue, not only in Europe where 94625 cases were reported in 2015, but worldwide. It has been estimated that Salmonella enterica causes approximately 1.2 million illnesses and 450 deaths per year in the United States (Carroll et al., 2017; Efsa and Ecdc, 2017). These figures highlight that additional improvement in the current analysis methodologies are still needed.

When talking about bacterial foodborne pathogens, official methods are based on classical microbiology which require several days for bacterial isolation and identification. These methods present the additional drawback of not being able of detecting viable but non-culturable bacteria (VBNC). Fast and reliable analytical methods are needed by both, the industry and control laboratories. The main objectives of such methods are to ensure the health of consumers, to easily determine whether a food product has been contaminated, and if possible, identify how 
and when this contamination occurred. This is needed in order to establish the proper corrective measures (Prado et al., 2016a). Molecular methods have, now for long, demonstrated capability of overcoming the limitations associated with culture based methods (Garrido-Maestu et al., 2014; Chapela et al., 2015; Valderrama et al., 2016), being polymerase chain reaction (PCR) the most widely used and accepted (Garrido et al., 2013; Ceuppens et al., 2014). Furthermore, there is an increase interest on the development of miniaturized devices that would allow in situ and/or economic monitoring of food products. However, miniaturization of PCR instrumentation, although possible and feasible (Jia et al., 2007; Wang et al., 2009; Ha and Lee, 2015), requires the capacity of accurate thermal cycling of the sample, since the speed of temperature transitions and the thermal homogeneity throughout the PCR mixture are essential for the run time, efficiency and specificity of the amplification reactions (Wittwer et al., 1990). Such demands concerning accurate thermal control, limit the number of materials that can be used for the fabrication of miniaturized devices (Jia et al., 2007), and consequently increase fabrication costs. Therefore, novel isothermal amplification techniques have emerged in recent years with the goal of providing an analytical solution to some of the drawbacks associated with PCR/qPCR, specially due to their simplicity and reduced thermal budget (Kaprou et al., 2015). Among them, loop-mediated isothermal amplification (LAMP) has become the most popular technique (Mori and Notomi, 2009; Fang et al., 2010b; Rafati and Gill, 2015).

It has been reported that in LAMP, along with specific DNA amplification, an insoluble by product is formed $\left(\mathrm{Mg}_{2} \mathrm{P}_{2} \mathrm{O}_{7}\right)$, what allows to directly determine if a particular reaction is positive or negative by naked-eye observation (Mori et al., 2001). However, several different approaches have been published, what indicates that it may not be as straightforward as expected, and thus requiring for trained analysts (Goto et al., 2009; Wan et al., 2012; Wang et al., 2012; Birmpa et al., 2015; Tanner et al., 2015). An alternative approach relies on the use of gold nanoparticles (AuNPs), which exhibit a characteristic localized surface plasmon resonance absorption band (LSPR) in the visible light region, being dependent on the interparticle distance (aggregation causes a red shift originating a red-to-purple color change) (Wong et al., 2014; Prado et al., 2016b). Wong et al. (2014), described a methodology based on the functionalization of AuNPs with 11-mercaptoundecanoic acid (MUA), which conferred negative charge to the surface of the particles. This, allowed to control aggregation/separation based on the presence/absence of $\mathrm{Mg}^{2+}$ in the LAMP reaction buffer (Wong et al., 2014), provided a visible color change and a more objective result assessment than turbidity.

The potential of microfluidics to create an integrated miniaturized and stand-alone laboratory has long been a dream of the community. This capability is particularly pertinent in low-resource settings where functional laboratories are simply not available (Chiu et al., 2017). Microfluidic technology is an enabling technology for Lab-On-a-Chip (LOC) tests as it allows to reduce sample/reagent consumption, integrated components and functions, and high portability and flexibility. One major challenge is that an easy-to-operate chip inevitably requires complicated fluid circuits and even microfabricated valves or pumps. Microfluidics provide a higher surface to volume ratio, a faster rate of mass and heat transfer, and the ability to precisely handle very small volumes of reagents (Foudeh et al., 2012; Sun et al., 2014). Microfluidic systems allow precise control of mixing in reduced sample volumes, integration with sensing elements, and provide the ideal conditions to develop a LOC systems for molecular detection of bacteria.

The aim of the current study was to determine the possibility of combining a miniaturized device for LAMP based DNA amplification, with functionalized AuNPs for naked-eye detection of Salmonella spp. in food samples. Additionally, its application in real food samples was also assessed, to determine its applicability in the food industry as a simple, inexpensive and fast analytical approach.

\section{MATERIALS AND METHODS}

\section{Sample Contamination}

In order to evaluate the performance of the methodology, food samples were artificially contaminated with $S$. Typhimurium CECT 4594, purchased from the Spanish Type Culture Collection. A pure culture was prepared by inoculating $4 \mathrm{~mL}$ of Buffered Peptone Water (BPW, Biokar Diagnostics S.A., France) with a single colony, and incubated overnight at $37^{\circ} \mathrm{C}$. After incubation, this culture was 10 -fold serially diluted in BPW and used for the inoculation of the food samples $(1 \mathrm{~mL}$ of the corresponding dilution was added to the mixture of $25 \mathrm{~g}$ of food sample and $225 \mathrm{~mL}$ of diluent), as well as plated on Tryptic Soy Broth (TSB, Biokar Diagnostics S.A., France) with 15 g/L of agar, to get viable bacterial counts. The plates were incubated at $37^{\circ} \mathrm{C}$ overnight.

\section{Food Sample Treatment and DNA Extraction}

To reach regulatory limits for most foodstuffs, regarding Salmonella spp. (absence/25 g, see European Regulation 2073/2005) a pre-enrichment step was included in the protocol. To this end, $25 \mathrm{~g}$ of sample were weighted and mixed with $225 \mathrm{~mL}$ of BPW. Positive samples were inoculated with $1 \mathrm{~mL}$ of the corresponding dilution of $S$. Typhimurium prepared as detailed above, homogenized for $30 \mathrm{~s}$ and incubated at $37^{\circ} \mathrm{C}$ for 18-24 h (negative samples were directly homogenized and placed in the incubator). After incubation, $1 \mathrm{~mL}$ was taken for DNA extraction. Chicken was selected as the reference food type for the determination of the Limit of Detection (LoD), and in addition to this, turkey, and omelet prepared with eggs were also included in the evaluation of the method. Food samples were obtained from local suppliers. A detailed list of the samples analyzed is provided in Table $\mathbf{1}$.

DNA extraction was performed as previously described by Garrido-Maestu et al. (2017). Briefly, the aliquot from the enriched matrix was centrifuged at 2,000 rpm for $2 \mathrm{~min}$, to eliminate large food debris. The supernatant was centrifuged at $13,000 \mathrm{rpm}$ for $5 \mathrm{~min}$, the pellet was rinsed with $1 \mathrm{~mL}$ of PBS and centrifuged again. The clean pellet was resuspended in $300 \mu \mathrm{L}$ of 
TABLE 1 | Samples inoculated with one single strain.

\begin{tabular}{lccc}
\hline Sample & N & Inoculum (cfu/25 g) & Result \\
\hline Chicken breast & $10^{*}$ & $<10$ & + \\
Chicken breast & 10 & - & - \\
Chicken breast & 2 & $<10$ & + \\
Chicken breast & 1 & $10^{3}-10^{4}$ & + \\
Chicken breast & 2 & $10^{4}-10^{5}$ & + \\
Chicken breast & 1 & $10^{7}-10^{8}$ & + \\
Turkey & 2 & - & + \\
Turkey & 1 & $<10$ & + \\
Turkey & 2 & $10-10^{2}$ & + \\
Turkey & 1 & $10^{3}-10^{4}$ & + \\
Omelet (egg) & 2 & $10^{2}-10^{3}$ & + \\
Omelet (egg) & 2 & $10^{7}-10^{8}$ & + \\
Omelet (egg) & 2 & & - \\
\hline
\end{tabular}

$N$ is the number of samples. *These samples were used for the determination of the LOD.

6\% Chelex ${ }^{\circledR} 100$ (w/v) (Bio-Rad Laboratories, Inc., United States), incubated at $56^{\circ} \mathrm{C}$ for $15 \mathrm{~min}$ at $1,000 \mathrm{rpm}$ in a Thermomixer comfort (Eppendorf AG, Germany), and finally the bacteria were lysed by heating at $99^{\circ} \mathrm{C}$ for $10 \mathrm{~min}$. After thermal lysis, the samples were centrifuged at $13,000 \mathrm{rpm}$ for $5 \mathrm{~min}$ at $4^{\circ} \mathrm{C}$, and the supernatant containing the DNA was transferred to a clean tube which was stored at $4^{\circ} \mathrm{C}$ until analysis.

\section{Microfluidic Device}

The fabrication of the microfluidic device was achieved through the combination of computer-numerical-control (CNC) polymer machining and polydimethylsiloxane (PDMS) replica molding. The CNC mold was designed using AutoCAD software, and fabricated in poly(methyl methacrylate) (PMMA) material using a CNC miller (FlexiCAM Viper 606). The PDMS prepolymer (Sylgard 184 silicone elastomer kit), was prepared by mixing the base and curing agent at a weight ratio of 10: 1 , then was poured onto the PMMA mold, placed under vacuum for $15-20 \mathrm{~min}$ to remove the air bubbles and cured in the oven at $65^{\circ} \mathrm{C}$ for $1 \mathrm{~h}$. After cooling down, the PDMS replica was peeled off from the mold and microfluidic channels were irreversibly sealed against a glass slide using oxygen plasma bonding. The final dimensions of the microfluidic device were $4 \mathrm{~mm}$ (thickness) $\times 76 \mathrm{~mm}$ (length) $\times 26 \mathrm{~mm}$ (width) and its pattern included a total of 8 capillarity-driven microchannels with a geometry of $40 \mathrm{~mm}$ (length) $\times 800 \mu \mathrm{m}($ depth $) \times 600 \mu \mathrm{m}$ (width). Each microchannel had one inlet and one outlet, incorporated in the PMMA mold, and a volume capacity of $20 \mu \mathrm{L}$.

\section{Gold Nanoparticle Synthesis and Characterization}

For the synthesis of spherical AuNPs the well-known Turkevich method was followed (Turkevich et al., 1951). Briefly, $5 \mathrm{~mL}$ of a $1 \%$ solution of trisodium citrate $\left(\mathrm{Na}_{3} \mathrm{C}_{6} \mathrm{H}_{5} \mathrm{O}_{7}\right.$, Sigma-Aldrich, St. Louis, MO, United States) was added to a boiling solution of gold chloride $\left(\mathrm{HAuCl}_{4} \cdot{ }_{3} \mathrm{H}_{2} \mathrm{O}\right.$, Sigma-Aldrich, St. Louis, $\mathrm{MO}$,
United States) (95 mL, $0.5 \mathrm{mM}$ ) under vigorous magnetic stirring. After $5 \mathrm{~min}$, the color of the solution turned from pale yellow to intense red.

The AuNPs were characterized by UV-Vis spectra using a NanoDrop 2000c (Thermo Fisher Scientific, Inc., Waltham, MA, United States). Additionally, the morphological characterization of the citrate-stabilized nanoparticles was performed by transmission electron microscopy (TEM). The images were acquired in a JEOL JEM-2100 electron microscope, operated at $200 \mathrm{kV}$. TEM samples were prepared by dropping ca. $12 \mu \mathrm{L}$ of the nanoparticles dispersion onto a formvar/carbon-coated $\mathrm{Cu}$ grid (400 mesh) placed on a filter paper followed by the evaporation of the solvent at room temperature.

\section{Gold Nanoparticle Functionalization}

The functionalization of the AuNP was performed as described by Wong et al. (2014). Briefly, $20 \mathrm{nM}$ AuNPs and $2 \mathrm{mM}$ MUA (freshly prepared in DMSO) were mixed, and incubated for $24 \mathrm{~h}$ at room temperature with constant agitation $(1400 \mathrm{rpm}$, Thermomixer comfort).

\section{Salmonella spp. DNA Amplification and Detection by Microfluidic-AuNP}

The detection of Salmonella spp. was assessed targeting invA gene. To this end, the primers designed by Hara-Kudo et al. (2005) were selected: FIP: GACGACTGGTA CTGATCGATAGTTTTTCAACGTTTCCTGCGG, BIP: CCGG TGAAATTATCGCCACACAAAACCCACCGCCAGG, F3: GG CGATATTGGTGTTTATGGGG, B3: AACGATAAACTGGACC ACGG.

A final reaction volume of $25 \mu \mathrm{L}$ was prepared with $3 \mu \mathrm{L}$ template DNA, $2.5 \mu \mathrm{L}$ of 10X Isothermal Amplification Buffer (New England BioLabs, Inc., Ipswich, MA, United States), 1 M betaine (Sigma-Aldrich, St. Louis, MO, United States), $0.35 \mathrm{mM}$ dNTP mix (Thermo Fisher Scientific, Inc., Waltham, MA, United States), and $8 \mathrm{U}$ Bst 2.0 WarmStart ${ }^{\circledR}$ DNA Polymerase (New England BioLabs, Inc., Ipswich, MA, United States). The primer concentration was 700 and $100 \mathrm{nM}$ for FIP/BIP and F3/B3 respectively. Out of the master mix prepared, $20 \mu \mathrm{L}$ were loaded in one of the microfluidic channels, which was carefully sealed with a glass slide and few clamps to avoid evaporation, and placed in a conventional laboratory incubator (Memmert $\mathrm{GmbH}$, Schwabach, Germany) with the temperature set at $65^{\circ} \mathrm{C}$ for $1 \mathrm{~h}$.

After incubation, $4 \mu \mathrm{L}$ of the LAMP product were diluted with sterile milli-Q water $(8.5 \mu \mathrm{L})$ and mixed with the functionalized AuNP (final concentration $6 \mathrm{nM}$ ), making a final volume of $15 \mu \mathrm{L}$. The results (positive-red, negative-purple) were directly assessed by naked-eye observation. For comparison purposes, gel electrophoresis was also performed; to do so a $2 \%$ agarose gel was prepared (NzyTech, Lisbon, Portugal) in Sodium Borate buffer prepared as previously described (SB, Brody and Kern, 2004). The gel was stained with $4 \mu \mathrm{L}$ of Midori Green (Nippon Genetics Europe $\mathrm{GmbH}$, Düren, Germany). One $\mu \mathrm{L}$ of the LAMPAuNP product was mixed with $5 \mu \mathrm{L}$ of $6 \mathrm{X}$ DNA loading dye (Thermo Fisher Scientific, Inc., Waltham, MA, United States), and loaded in the gel. The samples were separated for $20 \mathrm{~min}$ 
at $300 \mathrm{~V}$, and finally visualized in a GelDoc ${ }^{\mathrm{TM}} \mathrm{EZ}$ Imager (Bio-Rad Laboratories, Inc., United States). Finally, UV-vis was also measured for positive and negative samples in a NanoDrop 2000c.

\section{Fitness-for-Purpose of the Method}

Following the protocol described above, the complete method was evaluated taking into account the LoD, relative sensitivity (SE), specificity (SP) and accuracy (AC), positive and negative predictive values (PPV, NPV) and the kappa index of concordance $(k)$, as previously described (Tomas et al., 2009; Anderson et al., 2011; Garrido et al., 2013). To do so, every sample was classified as being in Positive, or Negative, Agreement (PA and NA) and Positive, or Negative, Deviation respect to the expected results (if the samples were, or not, inoculated with the target microorganism). Then the previously mentioned parameters were calculated based on the following formulas:

$$
\begin{aligned}
& \mathrm{SE}=[\mathrm{PA} /(\mathrm{PA}+\mathrm{ND})] \times 100 \\
& \mathrm{SP}=[\mathrm{NA} /(\mathrm{PD}+\mathrm{NA})] \times 100 \\
& \mathrm{AC}=[(\mathrm{PA}+\mathrm{NA}) / \mathrm{N}] \times 100
\end{aligned}
$$

where "N" number of analyzed samples.

$$
\mathrm{PPV}=[\mathrm{PA} /(\mathrm{PA}+\mathrm{PD})] \times 100
$$$$
\mathrm{NPV}=[\mathrm{NA} /(\mathrm{NA}+\mathrm{ND})] \times 100
$$$$
k=2 \times(\mathrm{PA} \times \mathrm{NA}-\mathrm{ND} \times \mathrm{PD}) /[(\mathrm{PA}+\mathrm{PD}) \times(\mathrm{PD}+\mathrm{NA})+
$$

$(\mathrm{PA}+\mathrm{ND}) \mathrm{x}(\mathrm{ND}+\mathrm{NA})]$.

The LoD was determined to be the lowest, reproducible, detectable concentration. The rest of the parameters were calculated based on the obtained and expected results.

\section{RESULTS}

\section{Microfluidics}

The microfluidic device, with eight channels was successfully designed and fabricated as can be observed in Figures 1a,b. The capillary-driven chip can perfectly hold $20 \mu \mathrm{L}$ of reaction mixture in each channel, and was carefully sealed by placing a second glass slide was placed on top, which was held with few clamps. This simple setup avoided evaporation of reagents as well as bubble formation in the channels, when performing the DNA amplification. The enzymatic reaction was not affected by the setup and run as expected.

\section{AuNP Synthesis and Characterization}

The correct synthesis of AuNPs was confirmed by UV-vis, showing a peak at $\approx 520 \mathrm{~nm}$, which was still present after MUA functionalization, as depicted in Figure 2. In addition to this, the AuNPs were visualized by TEM, confirming spherical morphology and an average size of $13.3 \pm 1.2 \mathrm{~nm}$ (see Figures 3a,b).

\section{Salmonella spp. Detection}

Successful DNA amplification was obtained in the microfluidic chip, as demonstrated by the typical LAMP banding pattern after gel electrophoresis (Figure 4a). Clear color differences
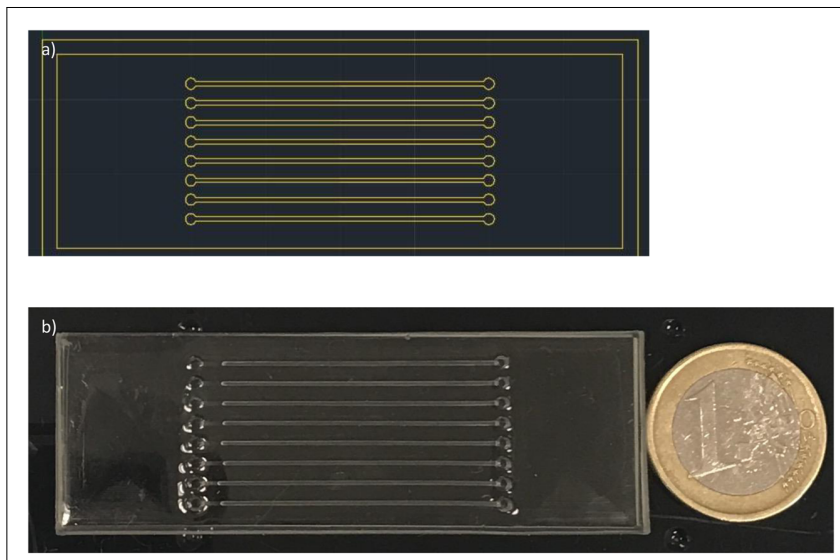

FIGURE 1 | Microfluidic device design and fabrication. (a) Schematic microfluidic chip designed with AutoCad. (b) Final PDMS microfluidic device (PDMS replica bonded against a glass slide).

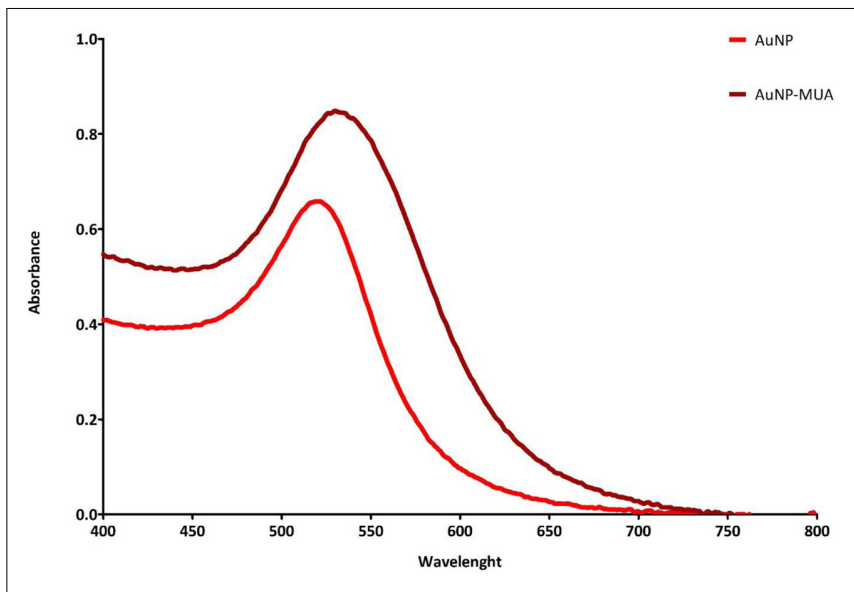

FIGURE 2 | UV-Vis of AuNPs before and after MUA functionalization.

[red (+) vs. purple $(-)$ ] can be observed after combination of functionalized AuNPs with the diluted LAMP amplification product, as shown in Figure 4b. These differences are also clearly visualized by UV-Vis, see Figure 4c.

\section{Method Evaluation}

The evaluation of the microfluidic-AuNP method demonstrated a LoD of $10 \mathrm{cfu} / 25 \mathrm{~g}$. In addition to this, all performance parameters evaluated (SE, SP, AC, PPV, NPV, and $k$ ) obtained excellent results when compared to the expected ones (100\%), further details are provided in Table 2.

\section{DISCUSSION}

The development and implementation of novel techniques, which allow in situ, fast and accurate detection of foodborne pathogens is highly desirable in the food industry. In the current study, the combination of microfluidic-LAMP DNA amplification with AuNP detection was assessed. 

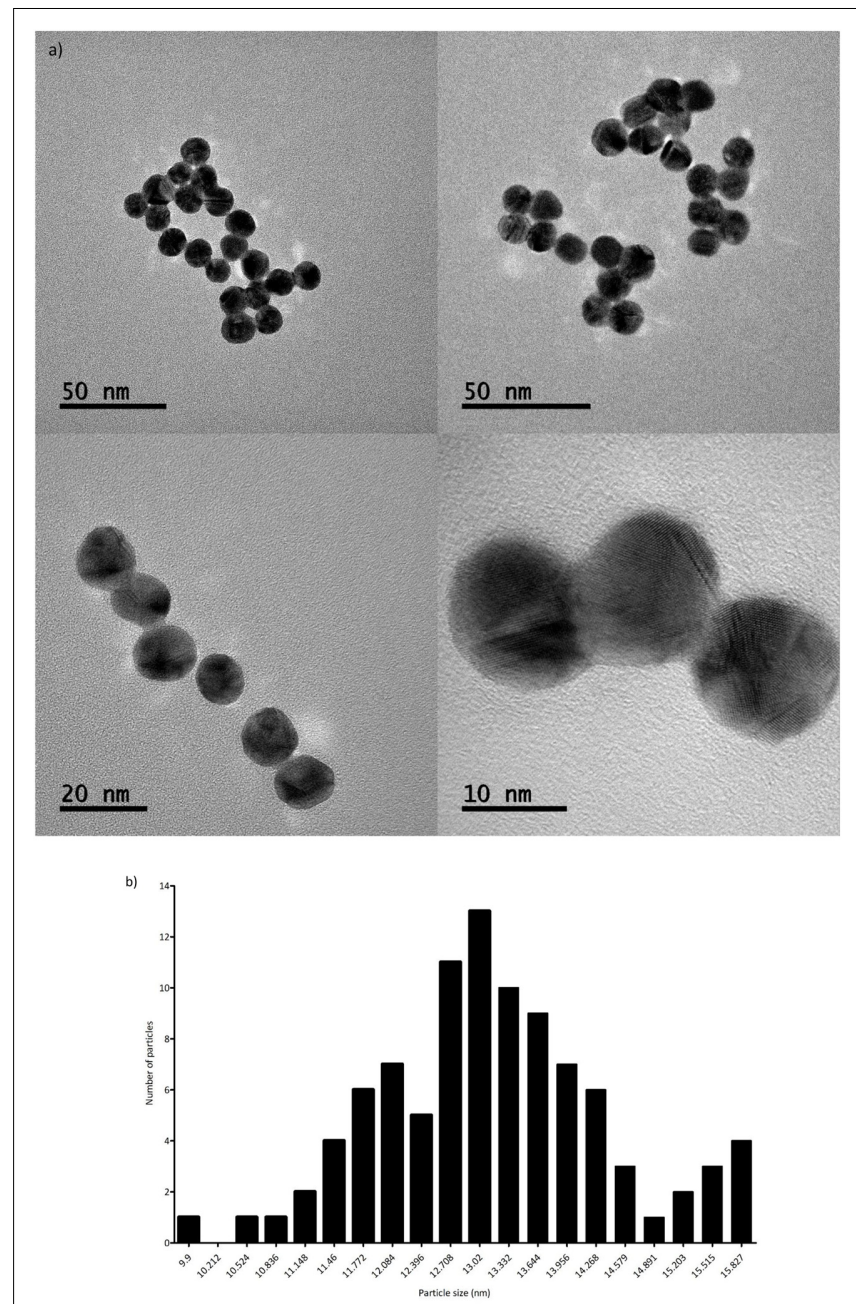

FIGURE 3 | (a) AuNP TEM images at different magnifications. (b) AuNPs size distribution, based on 96 measurements.

The construction of a microfluidic device was successfully accomplished and demonstrated to be suitable for LAMPbased DNA amplification. This approach allowed an increased specificity in bacteria detection, as it was demonstrated in a set of parallel experiments (data not shown). In these experiments, negative samples that were reacted with AuNPs in regular PCR tubes (DNase, RNase and pyrogen free, Nippon Genetics Europe GmbH, Duren, Germany) were determined to be positive; while when the microfluidic chip was used resulted negative, as expected. This may be explained by enhanced performance

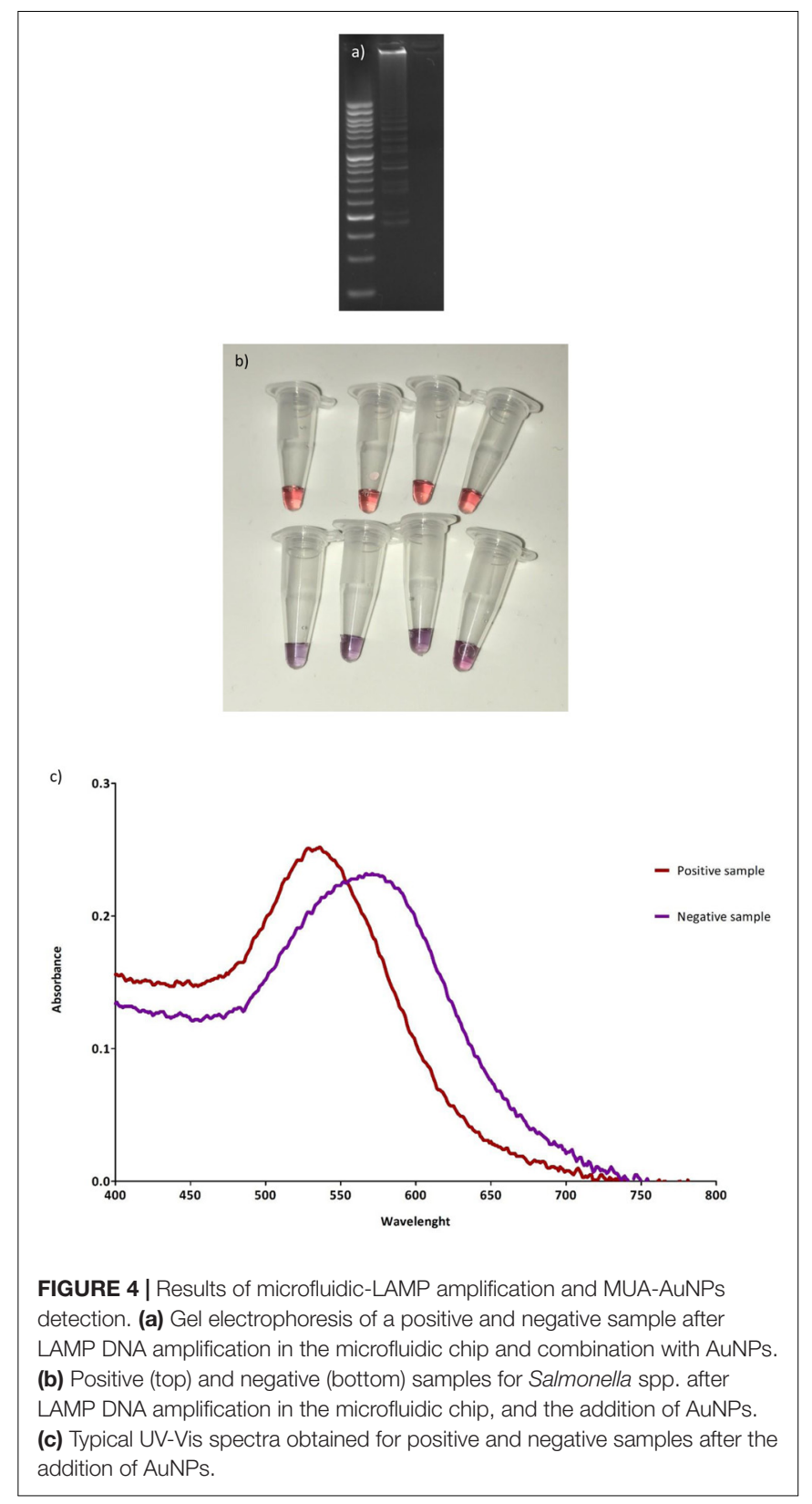

of the positive reactions due to the advantages of microfluidics previously commented (better heat transfer, controlled mixing and no gravity that prevented NP aggregation, etc.).

Wong et al. (2014) reported for the first time the combination of MUA and AuNPs as a naked-eye approach to asses

TABLE 2 | Method evaluation summary.

\begin{tabular}{|c|c|c|c|c|c|c|c|c|c|c|c|c|}
\hline Bacterium & Gen & $\mathbf{N}$ & PA & PD & NA & ND & SE & SP & AC & PPV & NPV & $\kappa$ \\
\hline S. Typhimurium CECT 4594 & invA & 38 & 24 & 0 & 14 & 0 & 100 & 100 & 100 & 100 & 100 & 1.00 \\
\hline
\end{tabular}

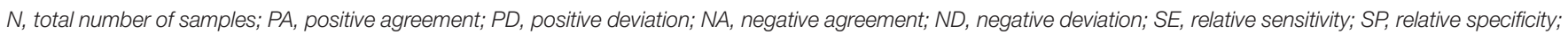

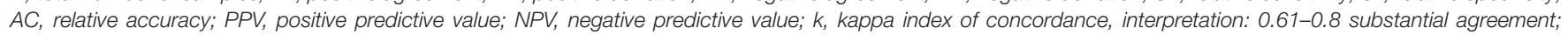
0.81-1.00 almost complete concordance according to Altman (1991) and Anderson et al. (2011). 
LAMP DNA amplification. In Wong et al. (2014) study, the functionalized AuNPs were added before the LAMP reaction, what caused particle aggregation. After DNA amplification, in order to see color differences ultrasounds had to be applied to re-disperse the particles in positive samples. This simple treatment, may be problematic when thinking on in situ analyses. In the current study, the addition of the AuNPs after DNA amplification, allowed to clearly observe the color changes without applying ultrasounds.

Recently, many studies were published combining LAMP amplification with DNA-functionalized AuNPs (Jaroenram et al., 2012; Arunrut et al., 2013, 2016; Seetang-Nun et al., 2013; Kumvongpin et al., 2016). Even though this approach is expected to present higher specificity, due to the incorporation of the DNA probe, the use of MUA is more economic, the functionalization protocol is easier, and these particles can be incorporated to any LAMP assay, thus expanding their direct applicability (we have tested the sample protocol targeting $S$. Typhimurium, $S$. Enteritidis and L. monocytogenes with comparable results in terms of LoD, SE, SP, AC, PPV, NPV and $k$, by just modifying the primers selected, data not shown).

The application of this methodology to Salmonella-spiked food samples allowed the reliable detection of the pathogen, even at low concentration $(10 \mathrm{cfu} / 25 \mathrm{~g})$, what is compatible with the needs of the food industry. These results are similar to those obtained with other conventional LAMP methods (Ohtsuka et al., 2005; D’Agostino et al., 2016; Garrido-Maestu et al., 2017), or even with other DNA amplification techniques (GonzálezEscalona et al., 2012; Maurischat et al., 2015; Zhang et al., 2015).

To the best of our knowledge this is the first study combining AuNPs, LAMP and microfluidics, which has undergone an extensive evaluation in food samples (LoD, SE, SP, AC, PPV, NPV, $k$ ), being critical for future implementation in the food industry. Previous studies have been just focused on the development of the methodology, but a thorough evaluation of its applicability in food products was missing (Fang et al., 2010a,b; Wong et al., 2014; Sayad et al., 2016; Park et al., 2017).

To summarize, in the current study we report the successful combination of microfluidic isothermal DNA amplification with AuNPs-based detection, allowing naked-eye discrimination, for the specific detection of Salmonella spp. In food samples. The

\section{REFERENCES}

Altman, D. G. (1991). Practical Statistics for Medical Research. New York, NY: Chapman and Hall.

Anderson, A., Pietsch, K., Zucker, R., Mayr, A., Muller-Hohe, E., Messelhausser, U., et al. (2011). Validation of a duplex real-time PCR for the detection of Salmonella spp. in different food products. Food Anal. Methods 4, 259-267. doi: 10.1016/j.ijfoodmicro.2013.05.012

Arunrut, N., Kampeera, J., Sirithammajak, S., Sanguanrut, P., Proespraiwong, P., Suebsing, R., et al. (2016). Sensitive visual detection of AHPND bacteria using loop-mediated isothermal amplification combined with DNA-functionalized gold nanoparticles as probes. PLOS ONE 11:e0151769. doi: 10.1371/journal. pone.0151769

Arunrut, N., Kampeera, J., Suebsing, R., and Kiatpathomchai, W. (2013). Rapid and sensitive detection of shrimp infectious myonecrosis virus using a reverse transcription loop-mediated isothermal amplification and visual results obtained indicate the suitability of the methodology for its implementation in the food industry. It is a simple, fast and inexpensive analytical approach for foodborne pathogen detection although an inter-laboratory validation is needed.

\section{AUTHOR CONTRIBUTIONS}

AG-M designed the experiments and wrote the manuscript. SA performed the DNA amplification experiments and AuNPs evaluation. LD and JC designed the microfluidic system and helped in the optimization of the DNA amplification within the system. SA-C, MP, and YK worked on the synthesis and functionalization of the AuNPs. EC-A and SA-C performed the characterization of the AuNPs by TEM. MP collaborated in the design of the experiments and evaluation of the results. All the co-authors collaborated in the proofreading of the final manuscript.

\section{FUNDING}

This work was supported by a Marie Curie COFUND Action (Project No: 600375. NanoTRAINforGrowth - INL Fellowship programme in nanotechnologies for biomedical, environment and food applications), by the EU Framework Programme for Research and Innovation H2020 COFUND, Grant Agreement 713640 , by the project Nanotechnology Based Functional Solutions (NORTE-01-0145-FEDER-000019), supported by Norte Portugal Regional Operational Programme (NORTE2020), under the PORTUGAL 2020 Partnership Agreement, through the European Regional Development Fund (ERDF).

\section{ACKNOWLEDGMENT}

Authors would like to thank Dr. Antonio Lozano-León, director of the Institute of Applied Microbiology-ASMECRUZ, for kindly providing the bacterial strains used in the current study, and the Microbiology and Bioassays Laboratory of ANFACOCECOPESCA for technical assistance.

colorogenic nanogold hybridization probe assay. J. Virol. Methods 193, 542-547. doi: 10.1016/j.jviromet.2013.07.017

Birmpa, A., Kalogeropoulos, K., Kokkinos, P., and Vantarakis, A. (2015). Evaluation of two loop-mediated isothermal amplification methods for the detection of Salmonella enteritidis and Listeria monocytogenes in artificially contaminated ready-to-eat fresh products. Ital. J. Food Saf. 4, doi: 10.4081/ijfs. 2015.5383

Brody, J. R., and Kern, S. E. (2004). Sodium boric acid: a Tris-free, cooler conductive medium for DNA electrophoresis. Biotechniques 36, 214-216.

Carroll, L. M., Wiedmann, M., den Bakker, H., Siler, J., Warchocki, S., Kent, D., et al. (2017). Whole-genome sequencing of drug-resistant Salmonella enterica isolated from dairy cattle and humans in New York and Washington states reveals source and geographic associations. Appl. Environ. Microbiol. 83:e14017. doi: 10.1128/AEM.00140-17

Ceuppens, S., Li, D., Uyttendaele, M., Renault, P., Ross, P., Van Ranst, M., et al. (2014). Molecular methods in food safety microbiology: Interpretation and 
implications of nucleic acid detection. Compr. Rev. Food Sci. Food Saf. 13, 551-577. doi: 10.1111/1541-4337.12072

Chapela, M., Garrido-Maestu, A., and Cabado, A. G. (2015). Detection of foodborne pathogens by qPCR: a practical approach for food industry applications. Cogent Food Agric. 1, 1-19. doi: 10.1080/23311932.2015.1013771

Chiu, D. T., Di Carlo, D., Doyle, P. S., Hansen, C., Maceiczyk, R. M., and Wootton, R. C. R. (2017). Small but perfectly formed? Successes, challenges, and opportunities for microfluidics in the chemical and biological sciences. Chem 2, 201-223. doi: 10.1016/j.chempr.2017.01.009

D'Agostino, M., Robles, S., Hansen, F., Ntafis, V., Ikonomopoulos, J., Kokkinos, P., et al. (2016). Validation of a loop-mediated amplification/ISO 6579-based method for analysing soya meal for the presence of Salmonella enterica. Food Anal. Methods 9, 2979-2985. doi: 10.1007/s12161-016-0602-7

Efsa, and Ecdc. (2017). The Euroean Union summary report on trends and sources of zoonsoes, zoonotic agents and food-borne outbreaks in 2015. EFSA J. 13, 4329.

Fang, X., Chen, H., Yu, S., Jiang, X., and Kong, J. (2010a). Predicting viruses accurately by a multiplex microfluidic loop-mediated isothermal amplification chip. Anal. Chem. 83, 690-695. doi: 10.1021/ac102858j

Fang, X., Liu, Y., Kong, J., and Jiang, X. (2010b). Loop-mediated isothermal amplification integrated on microfluidic chips for point-of-care quantitative detection of pathogens. Anal. Chem. 82, 3002-3006. doi: 10.1021/ac1000652

Foudeh, A. M., Didar, T. F., Veres, T., and Tabrizian, M. (2012). Microfluidic designs and techniques using lab-on-a-chip devices for pathogen detection for point-of-care diagnostics. Lab Chip 12, 3249-3266. doi: 10.1039/c2lc40630f

Garrido, A., Chapela, M. J., Román, B., Fajardo, P., Lago, J., Vieites, J. M., et al. (2013). A new multiplex real-time PCR developed method for Salmonella spp. and Listeria monocytogenes detection in food and environmental samples. Food Control 30, 76-85. doi: 10.1016/j.foodcont.2012.06.029

Garrido-Maestu, A., Chapela, M. J., Peñaranda, E., Vieites, J. M., and Cabado, A. G. (2014). In-house validation of novel multiplex real-time PCR gene combination for the simultaneous detection of the main human pathogenic vibrios (Vibrio cholerae, Vibrio parahaemolyticus, and Vibrio vulnificus). Food Control 37, 371-379. doi: 10.1016/j.foodcont.2013.09.026

Garrido-Maestu, A., Fuciños, P., Azinheiro, S., Carvalho, J., and Prado, M. (2017). Systematic loop-mediated isothermal amplification assays for rapid detection and characterization of Salmonella spp., Enteritidis and Typhimurium in food samples. Food Control 80, 297-306. doi: 10.1016/j.foodcont.2017. 05.011

González-Escalona, N., Brown, E. W., and Zhang, G. (2012). Development and evaluation of a multiplex real-time PCR (qPCR) assay targeting ttrRSBCA locus and invA gene for accurate detection of Salmonella spp. in fresh produce and eggs. Food Res. Int. 48, 202-20. doi: 10.1016/j.foodres.2012.03.009

Goto, M., Honda, E., Ogura, A., Nomoto, A., and Hanaki, K. I. (2009). Colorimetric detection of loop-mediated isothermal amplification reaction by using hydroxy naphthol blue. Biotechniques 46, 167-172. doi: 10.2144/000113072

Ha, M. L., and Lee, N. Y. (2015). Miniaturized polymerase chain reaction device for rapid identification of genetically modified organisms. Food Control 57, 238-245. doi: 10.1016/j.foodcont.2015.04.014

Hara-Kudo, Y., Yoshino, M., Kojima, T., and Ikedo, M. (2005). Loop-mediated isothermal amplification for the rapid detection of Salmonella. FEMS Microbiol. Lett. 253, 155-161. doi: 10.1016/j.femsle.2005.09.032

Jaroenram, W., Arunrut, N., and Kiatpathomchai, W. (2012). Rapid and sensitive detection of shrimp yellow head virus using loop-mediated isothermal amplification and a colorogenic nanogold hybridization probe. J. Virol. Methods 186, 36-42. doi: 10.1016/j.jviromet.2012.08.013

Jia, G., Siegrist, J., Deng, C., Zoval, J. V., Stewart, G., Peytavi, R., et al. (2007). A low-cost, disposable card for rapid polymerase chain reaction. Colloids Surf. B Biointerfaces 58, 52-60. doi: 10.1016/j.colsurfb.2007.03.007

Kaprou, G. D., Papadakis, G., Papageorgiou, D. P., Kokkoris, G., Papadopoulos, V., Kefala, I., et al. (2015). Miniaturized devices for isothermal DNA amplification addressing DNA diagnostics. Microsyst. Technol. 22, 1-6. doi: 10.1007/s00542015-2750-x

Kumvongpin, R., Jearanaikool, P., Wilailuckana, C., Sae-ung, N., Prasongdee, P., Daduang, S., et al. (2016). High sensitivity, loop-mediated isothermal amplification combined with colorimetric gold-nanoparticle probes for visual detection of high risk human papillomavirus genotypes 16 and 18. J. Virol. Methods 234, 90-95. doi: 10.1016/j.jviromet.2016.04.008
Maurischat, S., Baumann, B., Martin, A., and Malorny, B. (2015). Rapid detection and specific differentiation of Salmonella enterica subsp. enterica Enteritidis, Typhimurium and its monophasic variant 4,[5],12:i:- by real-time multiplex PCR. Int. J. Food Microbiol. 193, 8-14. doi: 10.1016/j.ijfoodmicro.2014. 10.004

Mori, Y., Nagamine, K., Tomita, N., and Notomi, T. (2001). Detection of loop-mediated isothermal amplification reaction by turbidity derived from magnesium pyrophosphate formation. Biochem. Biophys. Res. Commun. 289, 150-154. doi: 10.1006/bbrc.2001.5921

Mori, Y., and Notomi, T. (2009). Loop-mediated isothermal amplification (LAMP): a rapid, accurate, and cost-effective diagnostic method for infectious diseases. J. Infect. Chemother. 15, 62-69. doi: 10.1007/s10156-009-0669-9

Ohtsuka, K., Ohtsuka, K., Yanagawa, K., Yanagawa, K., Takatori, K., Takatori, K., et al. (2005). Detection of Salmonella enterica in naturally contaminated liquid eggs by loop-mediated isothermal amplification, and characterization of Salmonella isolates. Appl. Environ. Microbiol. 71, 6730-6735. doi: 10.1128/ AEM.71.11.6730

Park, B. H., Oh, S. J., Jung, J. H., Choi, G., Seo, J. H., Kim, D. H., et al. (2017). An integrated rotary microfluidic system with DNA extraction, loop-mediated isothermal amplification, and lateral flow strip based detection for point-ofcare pathogen diagnostics. Biosens. Bioelectron. 91, 334-340. doi: 10.1016/j.bios. 2016.11.063

Prado, M., Espiña, B., Fernandez-Argüelles, M. T., Diéguez, L., Fuciños, P., Vial, S., et al. (2016a). Detection of foodborne pathogens using nanoparticles. Advantages and Trends. Antimicrob. Food Packag. 183-201. doi: 10.1016/B9780-12-800723-5.00014-0

Prado, M., Ortea, I., Vial, S., Rivas, J., Calo-Mata, P., and Barros-Velázquez, J. (2016b). Advanced DNA-and protein-based methods for the detection and investigation of food allergens. Crit. Rev. Food Sci. Nutr. 56, 2511-2542.

Rafati, A., and Gill, P. (2015). Microfluidic method for rapid turbidimetric detection of the DNA of Mycobacterium tuberculosis using loop-mediated isothermal amplification in capillary tubes. Microchim. Acta 182, 523-530. doi: 10.1007/s00604-014-1354-y

Sayad, A. A., Ibrahim, F., Uddin, S. M., Pei, K. X., Mohktar, M. S., Madou, M., et al. (2016). A microfluidic lab-on-a-disc integrated loop mediated isothermal amplification for foodborne pathogen detection. Sens. Actuators B Chem. 227, 600-609. doi: 10.1016/j.snb.2015.10.116

Seetang-Nun, Y., Jaroenram, W., Sriurairatana, S., Suebsing, R., and Kiatpathomchai, W. (2013). Visual detection of white spot syndrome virus using DNA-functionalized gold nanoparticles as probes combined with loop-mediated isothermal amplification. Mol. Cell. Probes 27, 71-79. doi: 10.1016/j.mcp.2012.11.005

Sun, J., Xianyu, Y., and Jiang, X. (2014). Point-of-care biochemical assays using gold nanoparticle-implemented microfluidics. Chem. Soc. Rev. 43, 6239. doi: $10.1039 / C 4 C S 00125 G$

Tanner, N. A., Zhang, Y., and Evans, T. C. (2015). Visual detection of isothermal nucleic acid amplification using pH-sensitive dyes. Biotechniques 58, 59-68. doi: 10.2144/000114253

Tomas, D., Rodrigo, A., Hernandez, M., and Ferrus, M. A. (2009). Validation of real-time PCR and enzyme-linked fluorescent assay-based methods for detection of Salmonella spp. in chicken feces samples. Food Anal. Methods 2, 180-189. doi: 10.1007/s12161-009-9082-3

Turkevich, J., Stevenson, P. C., and Hillier, J. (1951). A study of the nucleation and growth processes in the synthesis of colloidal gold. Discuss. Faraday Soc. 11, 55-75. doi: 10.1039/df9511100055

Valderrama, W. B., Dudley, E. G., Doores, S., and Cutter, C. N. (2016). Commercially available rapid methods for detection of selected food-borne pathogens. Crit. Rev. Food Sci. Nutr. 56, 1519-1531. doi: 10.1080/10408398. 2013.775567

Wan, C., Yang, Y., Xu, H., Aguilar, Z. P., Liu, C., Lai, W., et al. (2012). Development of a propidium monoazide treatment combined with loopmediated isothermal amplification (PMA-LAMP) assay for rapid detection of viable Listeria monocytogenes. Int. J. Food Sci. Technol. 47, 2460-2467. doi: $10.1111 / j .1365-2621.2012 .03123 . x$

Wang, J.-H., Chien, L.-J., Hsieh, T.-M., Luo, C.-H., Chou, W.-P., Chen, P.-H., et al. (2009). A miniaturized quantitative polymerase chain reaction system for DNA amplification and detection. Sens. Actuators B Chem. 141, 329-337. doi: 10.1016/j.snb.2009.06.034 
Wang, L., Li, Y., Chu, J., Xu, Z., and Zhong, Q. (2012). Development and application of a simple loop-mediated isothermal amplification method on rapid detection of Listeria monocytogenes strains. Mol. Biol. Rep. 39, 445-449. doi: 10.1007/s11033-011-0757-7

Wittwer, C. T., Fillmore, G. C., and Garling, D. J. (1990). Minimizing the time required for DNA amplification by efficient heat transfer to small samples. Anal. Biochem. 186, 328-331. doi: 10.1016/0003-2697(90)90 090-V

Wong, J. K. F., Yip, S. P., and Lee, T. M. H. (2014). Ultrasensitive and closed-tube colorimetric loop-mediated isothermal amplification assay using carboxylmodified gold nanoparticles. Small 10, 1495-1499. doi: 10.1002/smll.20130 2348

Zhang, X., Du, X. J., Guan, C., Li, P., Zheng, W. J., and Wang, S. (2015). Detection of Vibrio cholerae by isothermal cross-priming amplification combined with nucleic acid detection strip analysis. Mol. Cell. Probes 29, 208-214. doi: 10.1016/ j.mcp.2015.05.001

Conflict of Interest Statement: The authors declare that the research was conducted in the absence of any commercial or financial relationships that could be construed as a potential conflict of interest.

Copyright (C) 2017 Garrido-Maestu, Azinheiro, Carvalho, Abalde-Cela, CarbóArgibay, Diéguez, Piotrowski, Kolen'ko and Prado. This is an open-access article distributed under the terms of the Creative Commons Attribution License (CC BY). The use, distribution or reproduction in other forums is permitted, provided the original author(s) or licensor are credited and that the original publication in this journal is cited, in accordance with accepted academic practice. No use, distribution or reproduction is permitted which does not comply with these terms. 